\title{
Robust adaptation to climate change
}

Wilby $^{1}$, R.L. and Dessai ${ }^{2,3}, \mathrm{~S}$.

${ }^{1}$ Department of Geography, Loughborough University, Leicestershire, UK

${ }^{2}$ School of Geography, University of Exeter, Exeter, UK

${ }^{3}$ Tyndall Centre for Climate Change Research, UK

Prepared for:

Weather

20 November 2009

Word count:

3361 (excluding references and figures)

\section{Corresponding author:}

Robert Wilby

Department of Geography,

Loughborough University,

Loughborough,

Leicestershire, LE11 3TU

UK

Tel +44 1509223093

e-mail: r.l.wilby@lboro.ac.uk 


\section{Introduction}

Coupled ocean/atmosphere general circulation models (OA/GCMs) have been instrumental in showing the need for global action to curb anthropogenic emissions that cause climate change. However, it may be contested that these tools have been less helpful in informing how to adapt at regional and local-scales (Schiermeier, 2007). Given the legacy of past emissions and prospect of unavoidable climate change, the case for committing more financial and technical resources to adaptation is gaining ground (UNDP, 2007; Parry et al., 2009). This poses a challenging question: How can we ensure that adaptation measures realise societal benefits now, and over coming decades, despite uncertainty about climate variability and change?

The scientific community is developing regional climate downscaling (RCD) techniques to reconcile the scale mismatch between coarse-resolution OA/GCMs and location-specific information needs of adaptation planners. The resulting "scenarios" are regarded as plausible descriptions of the future climate that reflect the influence of local topography and/or land-sea effects, and their interactions with changing synoptic-scale weather patterns under rising concentrations of greenhouse gases. Thanks to widely available and userfriendly tools, the volume of peer-reviewed research on RCD has grown dramatically over the last decade (see Wilby et al., 2009). However, it is becoming apparent that downscaling also has serious practical limitations, especially where the meteorological data needed for model calibration may be of dubious quality or patchy, the links between regional and local climate are poorly understood or resolved, and where technical capacity is not in place. Another concern is that high resolution downscaling can be misconstrued as accurate downscaling (Dessai et al., 2009). In other words, our ability to downscale to finer time and space scales does not imply that our confidence is any greater in the resulting scenarios.

The value of high resolution climate change scenarios for long-term planning may be questionable wherever climate variability is already stressing human and environmental systems. For instance, parts of North Africa and the Middle East are facing a water crisis due to rapid population growth, combined with weak governance, climate variability and limited renewable supplies. Under these circumstances, even achieving Millennium Development Goals (MDGs) by 2015 (such as access to safe drinking water) may seem a remote prospect, let alone sustaining progress under climate change to the 2020s and beyond. Hence, there have been calls to re-examine the ways in which climate risk information is used in adaptation and development planning (Dessai et al., 2005).

This paper begins by comparing two different approaches to climate risk assessment in adaptation planning. We then describe a framework for robust adaptation decision-making 
that departs from traditional "predict and provide" methods. We draw upon examples from the water sectors of developing and developed countries as evidence of how significant progress can be made in the majority of cases without climate change projections. Our views are also shaped by recent experiences of supporting adaptation in practice.

\section{Complementary approaches to adaptation}

Broadly speaking there are two main perspectives on climate risk assessment for adaptation. "Top-down" (also known as "scenario-led") methods involve first downscaling climate projections from OA/GCMs under a range of greenhouse gas emissions scenarios. The resulting local scenarios are then fed into impacts models (to estimate, for example, future stream flow or crop yields), before finally invoking adaptation measures to maximise any benefits or counter anticipated risks. The term "top down" is used because information is cascaded from one step to the next, with the number of permutations of emission scenario, climate model, downscaling method, and so on, proliferating at each stage (Figure 1). Although this is the most widely represented approach within the scientific evidence reviewed by the Intergovernmental Panel on Climate Change (IPCC), there are very few tangible examples of anticipatory or planned adaptation decisions arising from this route. The vast majority of research studies stop at the impact assessment stage.

One explanation may be that the range (or envelope) of uncertainty expands at each step of the process to the extent that potential impacts and their implied adaptation responses span such a wide range as to be practically unhelpful. Although more exhaustive characterization of uncertainty may be scientifically tractable (through international comparison studies involving large ensembles of climate models and downscaling methods such as PRUDENCE $^{1}$, ENSEMBLES ${ }^{2}$, NARCCAP $^{3}$ ), the prospect of reducing uncertainty depends on further progress being made in the underpinning climate science (Hawkins and Sutton, 2009). There also remains a danger that ensemble projections are perceived as actual probabilities of change when, in fact, the resultant distributions of temperature and precipitation changes are highly dependent upon the experimental design (Dessai and Hulme, 2004). Experience from the UK Climate Projections (UKCP09) tells us that, considerable time and effort must be invested in training user communities to discern the most appropriate scenarios and tools for the tasks in hand.

\footnotetext{
${ }^{1}$ http://prudence.dmi.dk/

2 http://ensembles-eu.metoffice.com/index.html

3 http://www.narccap.ucar.edu/
} 
"Bottom-up" methods focus on reducing vulnerability to past and present climate variability, typically in the wake of an extreme event or disaster (such as the floods of 1953 and 2000 in the UK). The term "bottom up" is used because the analysis begins with the factors and conditions that enable successful coping with climate-related threats at the level of individuals, households and communities. Although these responses do not depend on climate change scenarios, sufficiently lengthy observations are needed to assess magnitudes and frequencies of extreme events as well as their associated societal and/or environmental consequences (as in the case of the well-documented impacts of the 2003 summer heat-wave in Europe [Palutikof et al., 2004]). Formal records can be extended by anecdotal evidence of how severe weather has affected a community (e.g., the UK Climate Impacts Programme [2008] Local Climate Impacts Profiles), however, there is always a danger of over- or under-reporting of extreme events by local media.

In practice, climate vulnerability is determined by a host of factors including variations in wealth, social equality, food availability, health and education status, physical and institutional infrastructure, access to natural resources and technology (Brooks et al., 2005). Vulnerability indicators can be helpful in tracking changes in climate risk exposure and the effectiveness of adaptation strategies over time; indicators can also help to target resources on "hot spots". Adaptation occurs by improving coping strategies or by reducing exposure to known threats. Examples of the former might be upgrading flood forecasting systems or flood proofing individual homesteads against floods on riverine islands in Bangladesh, by constructing earth platforms (Tanner et al., 2007). An example of reducing exposure would be to lower the percentage of a population living in floodplains or low-lying coastal zones, by facilitating pro-poor economic migration. However, conventional vulnerability assessment are less suited to guiding adaptation if coping thresholds change, or climate risks emerge that are outside the range of recent experience. For example, successive drought years in India might progressively reduce coping thresholds of the rural poor by increasing indebtedness, or by deteriorating health linked to food scarcity. Later droughts will thus have a disproportionately greater impact on communities than earlier episodes.

\section{Adaptation options appraisal}

According to the IPCC Fourth Assessment Report (2007) there is a low level of consensus amongst climate models even about the sign of the change in seasonal rainfall over large parts of Africa, Asia and South America (Figure 2). When uncertainty in such an important variable is combined with the high vulnerability of populations, it makes sense to identify development strategies that perform well (though not necessarily optimally) over a wide 
range of conditions faced now and potentially in the future. Ideally "no regret" strategies should yield benefits regardless of climate change. In practice, there are opportunity costs, trade-offs, or externalities associated with adaptation actions so it is better to refer to such interventions as "low regret". Such measures should address present development priorities as well as keeping open or maximising options for adaptation in the future. For example, protecting water sources from contamination or salinization is a sound strategy under any climate context. Likewise, long-term monitoring of environmental quality is necessary for estimating the sustainable resource and for benchmarking changing conditions or the outcome of management decisions. Other examples of low regret water management measures are listed in Table 1. All make sense regardless of the very uncertain outlook for climatic and non-climatic drivers of water availability.

Here we propose a framework that sifts for robust adaptation measures that are low regret, or reversible, incorporate safety margins, employ 'soft' solutions (see below), are flexible and mindful of actions being taken by others to either mitigate or adapt to climate change (see Hallegatte, 2009). Assuming that the most significant risks posed by climate (and nonclimatic) hazards have been identified, the first step is to construct an inventory of all such adaptation options (labelled $A, B, C \ldots$ ) (Figure 3). This set could include hard engineering solutions and retrofit to existing infrastructure, as well as soft solutions involving re-allocation of resources, behaviour change, institutional and/or sectoral reform/restructuring, awareness-raising, or risk spreading via financial instruments (Wilby et al., 2009). Through screening and appraisal it should be possible to identify a sub-set of preferred adaptation measures (labelled $B, H, S$, and $W$ ) that would reduce vulnerability under the present climate regime, whilst being socially acceptable, technically, and economically feasible given the prevailing regulatory environment. If the life-time of the scheme is a few years or less, then it may be sufficient to test the measures using recent climatology. If the life-time of the measure spans multiple decades (as in the case of a new reservoir or irrigation system) then it is necessary to evaluate performance across a range of scenarios.

This is the point at which RCD might inform the options appraisal by establishing plausible upper and lower bounds to climate change sensitivity testing. Where impacts models are available, options' performance can be quantitatively analysed under different combinations of precipitation, temperature, sea level, etc. change as required. Other, non-climatic drivers (such as land-use change) might also be introduced to the sensitivity testing at this stage (e.g., Legesse et al., 2003). For many practical purposes, detailed numerical modelling may not be feasible (because of time, cost, technical constraints, etc.) or even necessary if the option delivers benefits regardless of the climate outlook (e.g., water saving measures). If no 
regional climate projections are available it may be necessary to revert to narratives about climate change from OA/GCMs (such as "warmer", "delayed melt", "more extremes").

Even qualitative descriptions of climate variability or the direction of change can help planners embrace uncertainty by looking for more resilient options that meet agreed standards. This thinking is evident in the first three principles of WWF's primer on Adapting Water Management, namely: 1) develop institutional capacity for effective governance; 2) create flexible [water] allocation systems and agreements, and; 3) reduce external nonclimate pressures (Matthews and Le Quesne, 2009). Measures that pass the sensitivity test and/or comply with accepted principles are then deemed to be robust to climate change (labelled $B$ and $W$ ). For example, using a narrative of "greater water scarcity" a programme of de-silting traditional water tanks was supported in preference to the construction of a new \$4billion dam in Andhra Pradesh, India (Pittock, 2008).

Given the long-term commitment to global mean temperature increases and sea level rise even if emissions are dramatically reduced in the short-term - adaptation strategies should be open-ended. Adaptive management of climate risks involves careful monitoring of the environment and systematic appraisal of the performance of measures (Figure 3). The resulting adaptation pathway will be shaped by the evolving scientific evidence and societal attitudes to risk. For example, scheduling of alternative flood defence options within the Thames Estuary 2100 (TE2100) Plan depends critically on future changes in key components of flood risk (i.e., sea level rise, tidal surge, fluvial flooding, and urban flash flooding). Large uncertainty is attached to all elements so the Plan was broken down into three phases: 1) maintaining and improving existing flood defences, plus safeguarding spaces for future flood management (2010-2034); 2) renewal and replacement of existing tidal defences (2035-2070); 3) continued maintenance of the existing system or construction of a new barrier (2070 onwards). The Plan is flexible to changing climate because interventions can be brought forward in time, alternative option pathways are not excluded, the design of structures can be modified, and land has been secured for new defences and habitat creation (Environment Agency, 2009a). Ten "triggers for change" will be monitored throughout the life of the Plan; if rapid change is detected in any indicator (such as mean sea level) the adaptation pathway can be adjusted accordingly.

The following examples further illustrate how principles of resilience, adaptive management, and monitoring are being incorporated in UK water management strategies. 


\section{Case study: Water management in England and Wales}

The UK water sector has been taking potential impacts of climate change into account for over a decade (see the review of Arnell and Delaney, 2006). Recent industry-agreed standards for water companies rest on suites of climate change factors that reflect some (but certainly not all) climate and hydrological modelling uncertainty (UKWIR, 2007). Climate change factors are used to adjust historic rainfall or river flow sequences. In the case of the River Itchen in southern England, the low flows (Q95) - which are critical to the survival of iconic species such as salmon - are on average expected to decrease by just $2 \%$ by the 2020s (Figure 4). However, the $90 \%$ confidence limits for the change in low flow span $+4 \%$ to $-24 \%$. The resulting deployable water supply estimates are then incorporated within water utilities' 25 year plans, alongside other drivers of the water supply-demand balance. The overall framework is a good example of the top-down, scenario-led approach.

Compared with tropical regions, there is a relatively high degree of consensus amongst climate models about the future direction of rainfall changes across the UK (see Figure 2). Even so, consensus does not necessarily equate with certainty, and there is still a wide range of projected impacts at the scale of individual water resource zones. For example, a study of the River Thames found that summer low flows could change by between $-19 \%$ and $+74 \%$ by the 2020 s (Wilby and Harris, 2006). Overall, $82 \%$ of the scenarios point to lower flows, and hence the possibility of diminished supplies at the time of peak demand and pressure on freshwater ecosystems. This leaves a water company with the choice of obtaining water supplies from new sources, taking steps to save water, or a combination of both. But what about the other $18 \%$ chance of higher flows in summer? If realised, any investments in new infrastructure (based only on the climate change driver) could be a costly mal-adaptation.

This simple example highlights the benefit of testing the sensitivity of adaptation decisions to a plausible range of climate change projections. Referring back to Figure 3 , the process begins by compiling as complete a list as possible of all the economically, politically, socially and environmentally viable adaptation options. The performance of individual and combinations of measures can then be tested under different climate conditions using impact models. Using this methodology it was found that adaptation options within Anglian Water Services' 25 year Water Resource Plan (2004) for East Suffolk and Essex were robust to most of the sampled climate change uncertainties (Dessai and Hulme, 2007). A similar study of the Wimbleball water resource zone in southwest England used the super-ensemble of the ClimatePrediction.net experiment to test the performance of different options (e.g., water saving, reduced environmental flows, increased reservoir storage) under climate change 
(Lopez et al., 2009). By comparing the frequency of failures to meet average and peak water demand in autumn it was found that simply increasing reservoir capacity was not enough to tackle successive dry-years; demand reduction measures were also needed.

Climate insensitive approaches figure prominently in the most recent Water Resources Strategy for England and Wales (Environment Agency, 2009b). Although the report contains an illustrative projection of the impact of climate change on mean naturalised flows by 2050 , much of the document is devoted to improving resilience of water supplies and critical infrastructure. Table 2 gives examples of some of the measures envisaged. As with the generic options in Table 1, none of the proposed adaptation measures is "no regret" because there are certainly costs attached to each. However, a shift of emphasis from supply- to demand-side management favours options that are robust to the uncertainty in climate change projections. In practice, climate change is just one pressure amongst many affecting the water supply-demand balance, so the cost-benefit of different adaptation configurations must still be tested for different types of society and governance.

Finally, it is noted that sensitivity testing is also being applied in a review of climate change allowances used by flood engineers (Reynard et al., 2009). Current Defra guidance (set out in the FCDPAG3 supplementary note ${ }^{4}$ ) requires all flood management plans in England and Wales to allow for climate change by incorporating, within a cost-benefit analysis, an increase in river flows of up $20 \%$ over the next 50 years, and beyond. The allowance was based on detailed climate impacts modelling and a review of the available scientific evidence at the time. The policy review is being informed by modelled changes in the 20-year flood across the breadth of climate projections held in IPCC and UKCP09 archives. The analysis shows (for different types of catchment) the fraction of scenarios that could lead to peak river flows above the existing precautionary allowance. Any decision to modify the allowance (nationally or regionally) will depend on what is deemed an acceptable flood risk, as well as on the financial implications of different standards of protection.

\section{Conclusions}

This paper has provided an overview of different approaches to climate risk assessment and adaptation with reference to examples from the water sector: scenario-led, vulnerabilitybased, and a combination of the two. It is accepted that adapting to climate change involves

\footnotetext{
${ }^{4}$ http://www.defra.gov.uk/environ/fcd/pubs/pagn/climatechangeupdate.pdf
} 
rejecting basic assumptions about stationary conditions that have underpinned earlier flood, water and conservation management (Milly et al., 2008). However, opinion is divided on how best to move forwards. Some argue for increased sophistication and higher resolution climate models to better characterise and constrain uncertainty in the regional climate projections offered to decision-makers ${ }^{5}$. Others assert that simply coping with present climate variability is enough of a challenge (Washington et al., 2006).

We suggest that significant benefits may accrue by allowing adaptation options appraisal to take centre stage, rather than climate change scenarios. In the majority of cases, simple steps can be taken to review options that make sense today and are likely to be beneficial in the future, whatever the climate outlook. This is not an anti- climate science perspective, rather pro- adaptation that is practicable. In fact, the same families of climate modelling and downscaling are already providing operational support to water and agricultural planning in the form of seasonal forecasts for drought prone regions such as Nordeste Brazil ${ }^{6}$. Over decadal time-frames, even uncertain climate change projections can bound sensitivity testing of options, but this involves a shift of emphasis from identifying optimal- to robust adaptations (Lempert et al., 2004).

Finally, many of our examples of adaptation incorporate flexibility, monitoring and review. How does this differ from best water management practice? Very little, except this is an era in which sustainable water management is being hampered by degrading instrumented networks and limited data sharing across some of the world's most vulnerable regions.

\footnotetext{
${ }^{5}$ See for example a recent Blogs and Opinion page of the UK's Natural Environment Research Council (http://planetearth.nerc.ac.uk/blogs/story.aspx?id=503) or the statement issued by the 6-9 May 2008 World Modelling Summit for Climate Prediction jointly organized by the World Climate Research Programme, World Weather Research Programme, and the International Geosphere-Biosphere Programme (http://wcrp.ipsl.jussieu.fr/Workshops/ModellingSummit/Documents/FinalSummitStat 6 6.pdf).

${ }^{6}$ See for example the operational system of the Ceará State Foundation for Meteorology and Water Resources (FUNCEME) in NE Brazil: http://www.funceme.br/DEMET/index.htm
} 


\section{References}

Arnell, N.W. and Delaney, K., 2006. Adapting to climate change: water supply in England and Wales. Climatic Change, 78, 227-255.

Brooks, N., Adger, W.N. and Kelly, P.M. 2005. The determinants of vulnerability and adaptive capacity at the national level and the implications for adaptation. Global Environmental Change, 15, 151-163.

Defra, 2009. Regionalised impacts of climate change on flood flows: rationale for definition of climate change scenarios and sensitivity framework. Joint Defra/EA Flood and Coastal Erosion Risk Management R\&D Programme, FD2020 project note, 39pp.

Dessai, S. and Hulme, M. 2004. Does climate adaptation policy need probabilities? Climate Policy, 4, 107-128.

Dessai, S. and Hulme, M. 2007. Assessing the robustness of adaptation decisions to climate change uncertainties: A case study on water resources management in the East of England. Global Environmental Change, 17, 59-72.

Dessai, S., Hulme, M., Lempert, R. and Pielke, R. 2009. Climate prediction: a limit to adaptation? In: Adger, N., Lorenzoni, I. and O'Brien, K. (eds.) Adapting to Climate Change: Thresholds, Values, Governance. Cambridge University Press, UK.

Dessai, S., Lu, X. and Risbey, J.S. 2005. On the role of climate scenarios for adaptation planning. Global Environmental Change, 15, 87-97.

Environment Agency (EA), 2009a. TE2100 Plan Consultation Document. Thames Barrier, London.

Environment Agency (EA), 2009b. Water for people and the Environment. Water Resource Strategy for England and Wales, Environment Agency, Bristol, 88pp.

Hallegatte, S. 2009. Strategies to adapt to an uncertain climate change. Global Environmental Change, 19, 240-247.

Hawkins, E. and Sutton, R. 2009. The potential to narrow uncertainty in regional climate predictions. Bulletin of the American Meteorological Society, early online release, doi:10.1175/2009BAMS2607.1.

Intergovernmental Panel on Climate Change (IPCC), 2007. Summary for Policy Makers. Climate Change 2007: The Physical Science Basis. Contribution of Working Group II to the Fourth Assessment Report of the Intergovernmental Panel on Climate Change, Cambridge University Press, UK.

Legesse, D., Vallet-Coulomb, C. and Gasse, F. 2003. Hydrological response of a catchment to climate and land use changes in tropical Africa: Case study south central Ethiopia. Journal of Hydrology, 275, 67-85.

Lempert, R., Nakicenovic, N., Sarewitz, D. and Schlesinger, M. 2004. Characterizing climate-change uncertainties for decision-makers. Climatic Change, 65, 1-9.

Lopez, A., Fung, F., New, M., Watts, G., Weston, A. and Wilby, R.L. 2009. From climate model ensembles to climate change impacts: A case study of water resource management in the South West of England. Water Resources Research, 45, W08419, doi:10.1029/2008WR007499.

Matthews, J. and Le Quesne, T. 2008. Adapting water to a changing climate. WWF International, Gland, Switzerland, 25pp

Milly, P.C.D., Betancourt, J., Falkenmark, M., Hirsch, R.M., Kundzewicz, Z.W., Lettenmaier, D.P. and Stouffer, R.J. 2008. Stationarity is dead: Whither water management? Science, 
$319,573-574$.

Palutikof, J.P., Agnew, M.D. and Hoar, M.R. 2004. Public perceptions of unusually warm weather in the UK: impacts, responses and adaptations. Climate Research, 26, 43-59.

Parry, M., Lowe, J. and Hanson, C. 2009. Overshoot, adapt and recover. Nature, 485, 11021103.

Pittock, J. (ed.) 2008. Water for life: Lessons for climate change adaptation from better management of rivers for people and nature. WWF International, Gland, Switzerland, 33pp.

Reynard, N.S., Crooks, S.M., Kay, A.L., Prudhomme, C., Donovan, B., Hardy, K. and Wilby, R.L. 2009. Regionalisation of climate impacts on flood flows to support the development of climate change guidance for flood management. Proceedings of the 44th Defra Flood and Coastal Management Conference, Telford, UK.

Schiermeier, Q. 2007. Get practical, urge climatologists. Nature, 448, 234-235.

Tanner, T., Nair, S., Bhattacharjya, S., Srivastava, S.K., Sarthi, P.P., Sehgal, M. and Kull, D. 2007. ORCHID: Climate risk screening in DFID India. Research Report. Institute of Development Studies, Brighton, 49pp.

UK Climate Impacts Programme, 2008. A Local Climate Impacts Profile: LCLIP. Oxford, UK. http://www.ukcip.org.uk/images/stories/Pub pdfs/lclip.pdf

UKWIR, 2007. Effects of Climate Change on River Flows and Groundwater Recharge, a Practical Methodology: Synthesis Report. UKWIR Report 07/CL/04/10.

United Nations Development Programme (UNDP), 2007. Human Development Report 2007/2008. Fighting climate change: Human solidarity in a divided world.

Washington, R., Harrison, M., Conway, D., Black, E., Challinor, A., Grimes, D., Jones, R., Morse, A., Kay, G. and Todd, M. 2006. African climate change: taking the shorter route. Bulletin of the American Meteorological Society, 87, 1355-1366.

Wilby, R.L. and Harris, I. 2006. A framework for assessing uncertainties in climate change impacts: low flow scenarios for the River Thames, UK. Water Resources Research, 42, W02419, doi:10.1029/2005WR004065.

Wilby, R.L., Troni, J., Biot, Y., Tedd, L., Hewitson, B.C., Smith, D.G. and Sutton, R.T. 2009. A review of climate risk information for adaptation and development planning. International Journal of Climatology, 29, 1193-1215. 
Table 1 Examples of "low regret" adaptation measures for water management

\section{Scientific and climate risk information}

- Centralise meteorological data collection, quality control and dissemination

- Support meteorological data rescue and digitization

- Monitor baseline and environmental change (indicators) at reference sites

- Improve surface and groundwater models leading to more reliable resource estimates

- Improve understanding of regional climate controls and land surface feedbacks

- Develop real-time, seasonal and decadal forecasting capability

- Improve the dissemination and uptake of forecasts for emergency management

- Survey at high resolutions to identify zones most vulnerable to coastal and fluvial flooding

\section{Water management practices}

- Strengthen water governance and methods of allocation

- Undertake source protection from pollution and salinization

- Increase agricultural (and urban) drainage water re-use

- Manage artificial aquifer recharge

- Undertake asset management and maintenance (leakage control, urban drainage systems)

- Improve water efficiency (domestic, agricultural, industrial sectors)

- Develop faster growing and/or more drought resistant crop cultivars

- Employ traditional water harvesting and retention techniques (such as terracing)

- Test contingency plans and improve post disaster management 
Table 2 Examples of actions to manage water resources and protect the environment in the face of climate change. Adapted from: Environment Agency (2009b).

\section{Actions}

- Compulsorily convert all permanent abstraction licenses to time-limited status, to provide the flexibility to respond to climate change.

- Increase the connectivity of water supply infrastructure to improve resilience of existing resources and provide additional security from extreme events.

- All abstractors to consider accepting a reduction in the reliability of supply as an option for resolving future deficits.

- Increase levels of metering with suitable tariffs to improve water and economic efficiency whilst protecting vulnerable groups.

- Support water neutrality where new development is planned and require developers to produce water cycle studies where housing developments are proposed.

- Identify water efficiency standards for non-household buildings at a regulatory level and a voluntary code beyond that.

- Further leakage control based on alternative methods of setting targets that better reflect the costs to society and the environment.

- Introduce further incentives for the purchase and fitting of water efficient equipment and appliances. 
Figure $1 \mathrm{~A}$ cascade of uncertainty proceeds from different socio-economic and demographic pathways, their translation into concentrations of atmospheric greenhouse gas (GHG) concentrations, expressed climate outcomes in global and regional models, translation into local impacts on human and natural systems, and implied adaptation responses. The increasing number of triangles at each level symbolise the growing number of permutations and hence expanding envelope of uncertainty. For example, even relatively reliable hydrological models can yield very different results depending on the methods (and observed data) used for calibration.

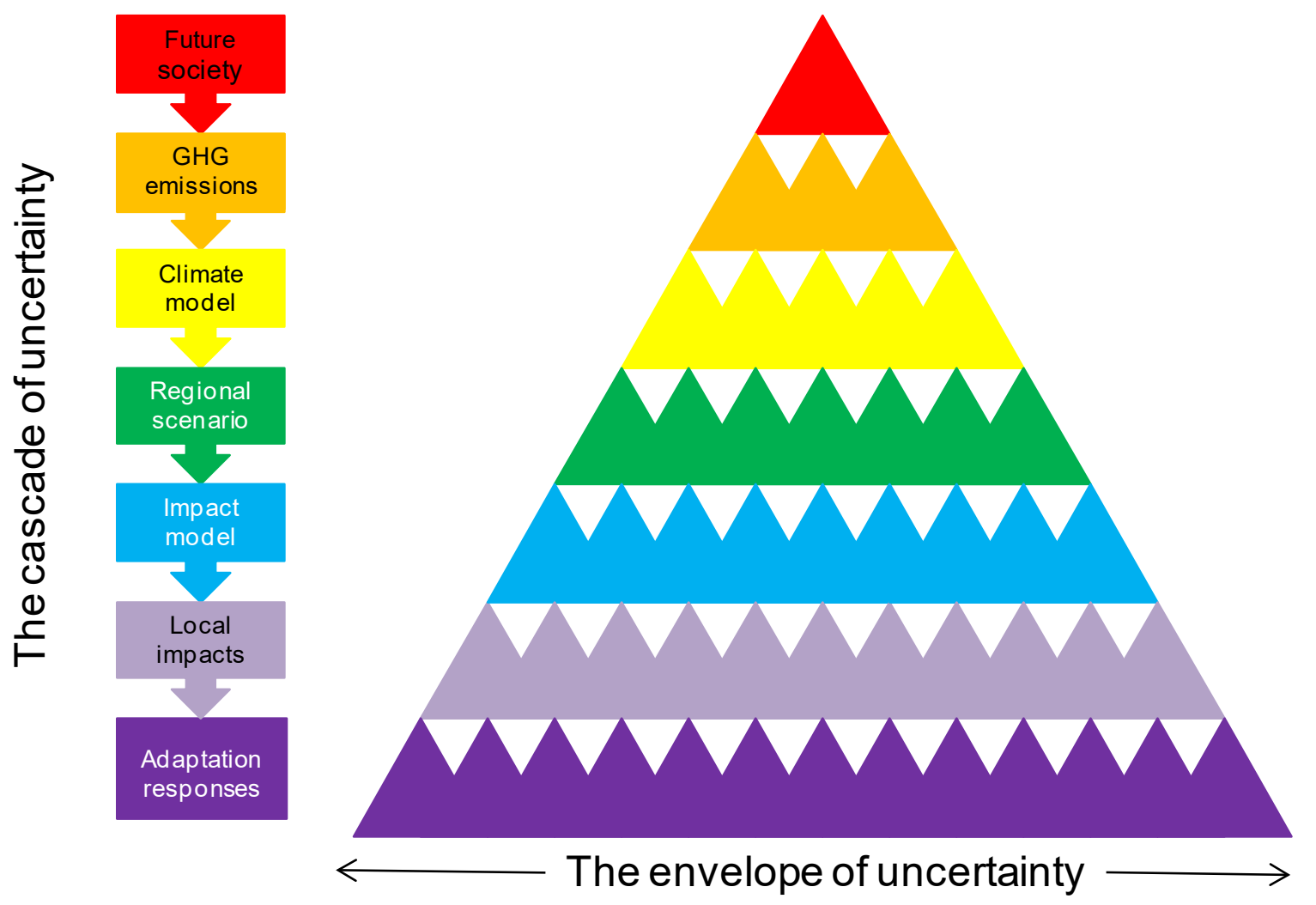


Figure 2 Changes in precipitation (\%) for the period 2090-2099, relative to 1980-1999. Values are multi-model averages based on the SRES A1B scenario for December to February (left) and June to August (right). White areas are where less than $66 \%$ of the models agree in the sign of the change and stippled areas are where more than $90 \%$ of the models agree in the sign of the change. Source: IPCC (2007).

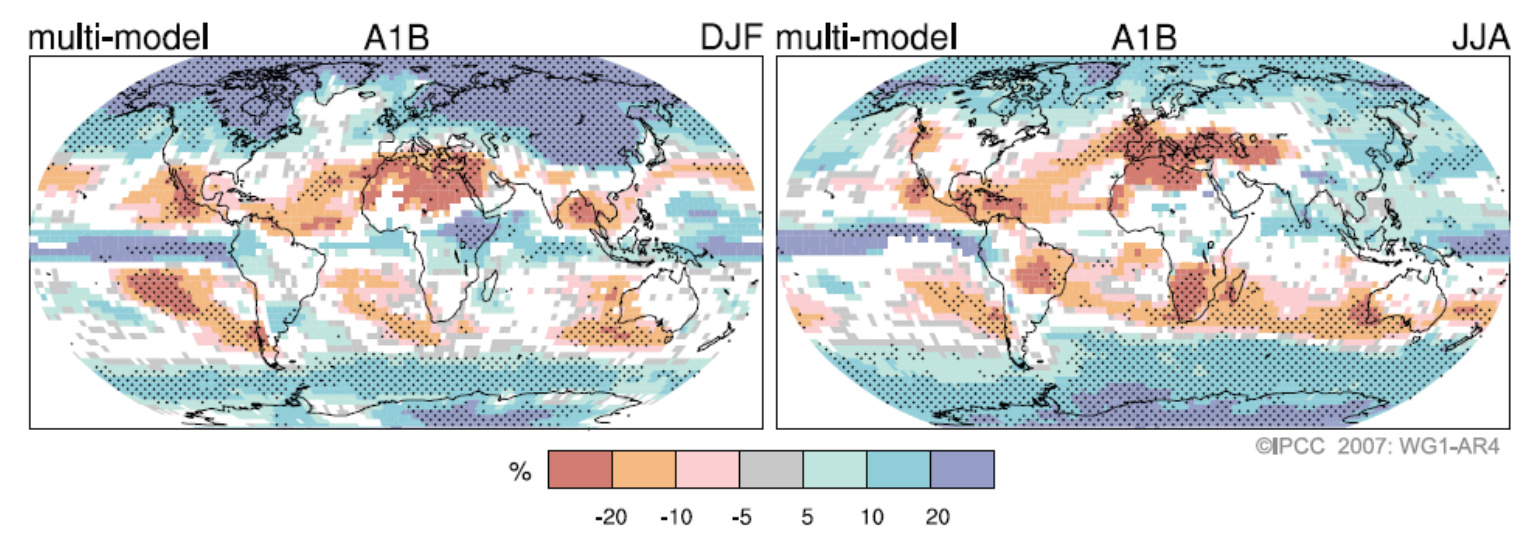


Figure 3 Conceptual framework for a scenario-neutral approach to adaptation planning.

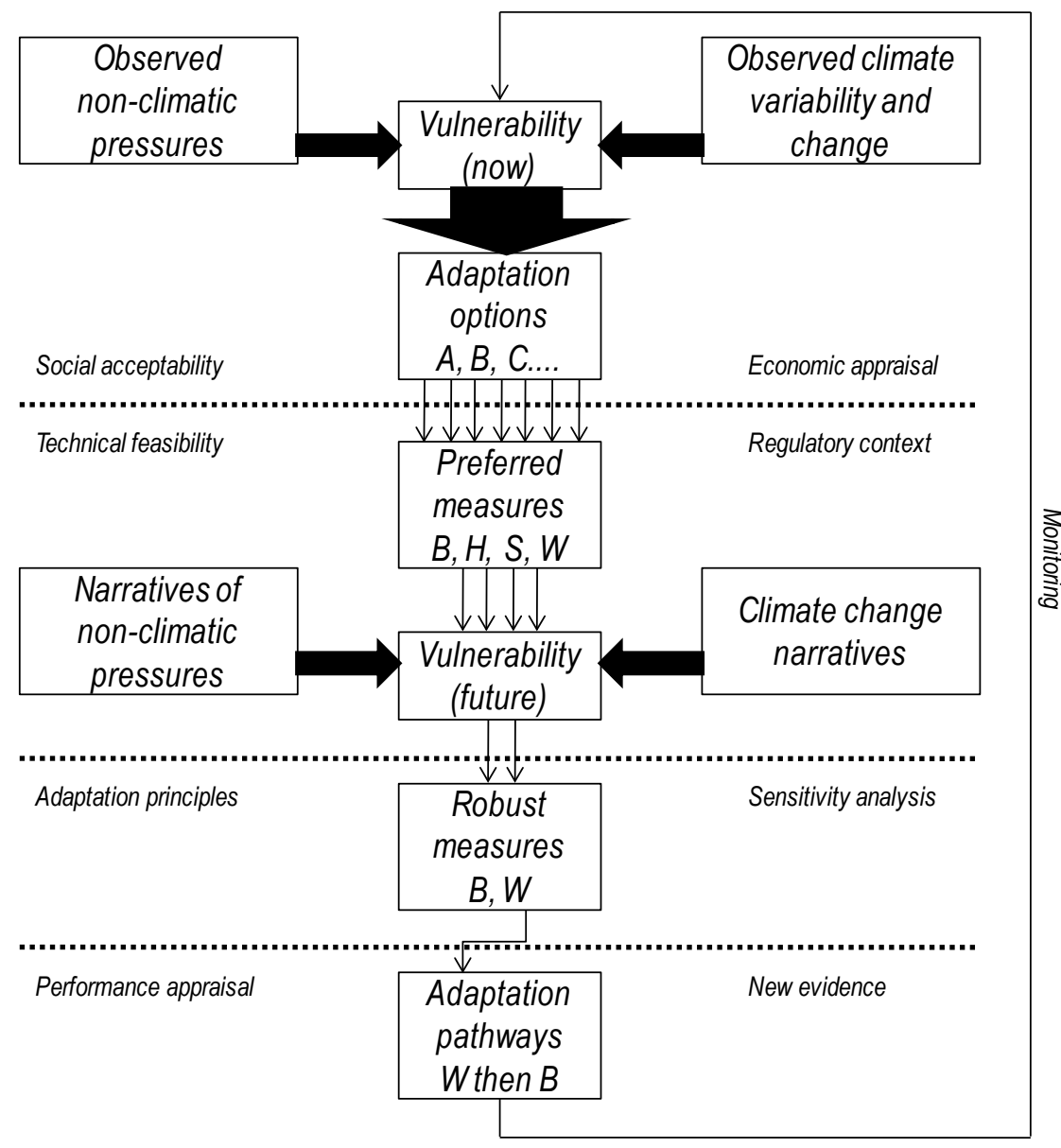


Figure 4 Climate change flow factors for the River Itchen at Highbridge, UK. The filled black circles show the central estimate of the changes based on an ensemble of climate and hydrological model simulations. The other symbols show the 5th, 25th, 75th percentiles, alongside three marker scenarios (dry, wet and median). The final bar (Q95) shows the central estimate and range of uncertainty in the river flow that is exceeded $95 \%$ of the time. Source: UKWIR (2007).

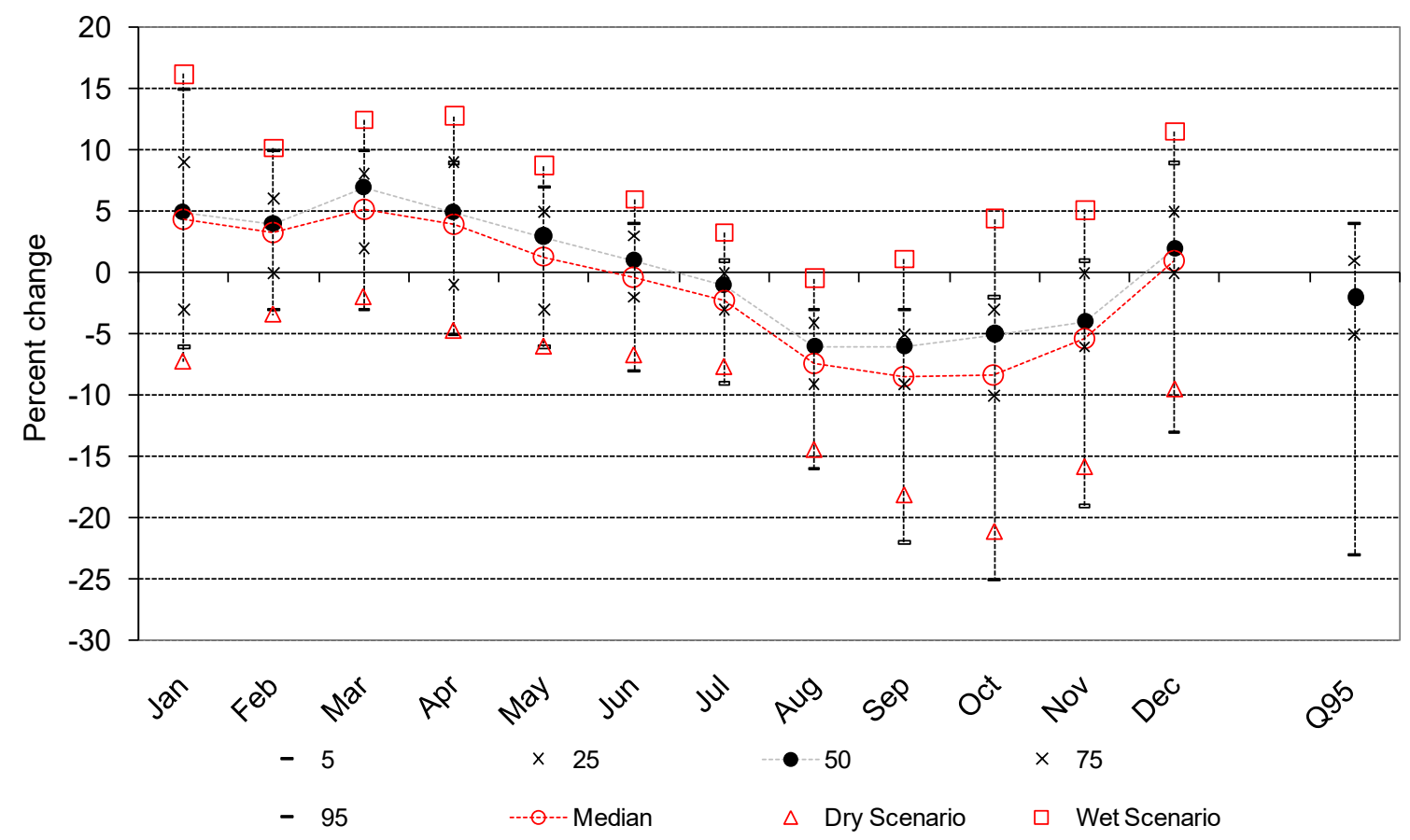

